Check for updates

Cite this: RSC Adv., 2019, 9, 39119

Received 19th October 2019

Accepted 18th November 2019

DOI: 10.1039/c9ra09332j

rsc.li/rsc-advances

\section{Sequential cycloaddition and ring expansion reaction of arynes and methylenebenzothiopheneones: synthesis of a benzo-fused eight-membered ring via sulfonium ylides $\dagger$}

\author{
Peng Xiao, ${ }^{a}$ Shikuan Su, ${ }^{a}$ Wei Wang, ${ }^{a}$ Weiguo Cao, ${ }^{a}$ Jie Chen, ${ }^{a}$ Jian Li (iD *a \\ and Yali Chen (DD *ab
}

A sequential cycloaddition and ring expansion of arynes and methylenebenzothiopheneones has been disclosed. This strategy proceeds through a sulfonium ylides intermediate and allows for the efficient synthesis of a sulfur-containing benzo-fused eight-membered ring.
As leading biologically relevant structural components, organosulfur compounds are widely present in many pharmaceuticals and bioactive compounds. ${ }^{1}$ Accordingly, sulfur-containing compounds have found their medical applications including as antibacterials, anti-inflammatories, dermatologics, and cancer treatments. A survey of the structures of compounds among the top 200 brand name drugs by U.S. retail sales (RS) in 2011 revealed that $24.8 \%$ of the drugs contain sulfur. The list included the famous Plavix (blood thinner, no. 2) and Seroquel (antipsychotic drug, no. 6). ${ }^{2}$ In addition, the benzothiazepinecontaining drug diltiazem (calcium channel blocker) is used in the treatment of hypertension and angina (Scheme 1). ${ }^{3}$ On the other hand, Et743 as a sulfur-containing marine natural product was also used as an effective drug for the treatment of advanced soft tissue sarcoma. ${ }^{4}$ As a consequence, many efforts have been devoted to the synthesis of such skeletons.

Arynes are recognized as one of the most reactive intermediates in organic synthesis. The past years have witnessed a great progress with respect to the carbon-carbon and carbonheteroatom bond-forming reactions involving arynes. ${ }^{5,6} \mathrm{~A}$ careful literature screening revealed that reactions involving the insertion of aryne into $\mathrm{C}-\mathrm{C}, \mathrm{C}-\mathrm{N}, \mathrm{C}-\mathrm{O}, \mathrm{C}-\mathrm{S}$, and other bonds have been well documented. ${ }^{7-9}$ Furthermore, the aryne-based Diels-Alder reaction, $[2+5]$, nucleophilic addition and

\footnotetext{
${ }^{a}$ Department of Chemistry, Innovative Drug Research Center, College of Sciences \& Institute for Sustainable Energy, Shanghai University, 99 Shangda Road, Shanghai 200444, P. R. China.E-mail: ylchen@staff.shu.edu.cn; lijian@shu.edu.cn

${ }^{b}$ Key Laboratory of Synthetic Chemistry of Natural Substances, Shanghai Institute of Organic Chemistry, Chinese Academy of Sciences, Shanghai 200444, P. R. China

$\dagger$ Electronic supplementary information (ESI) available: NMR, HRMS (ESI) and X-ray crystal structure data (CIF) for compound 5j, 5n. CCDC 1915323 for compound 5j; 1915320 for compound 5n. For ESI and crystallographic data in CIF or other electronic format see DOI: 10.1039/c9ra09332j
}

annulation reactions. ${ }^{8,9}$ Among $[2+8]$ and many other pericyclic reactions have been intensively investigated for the construction of various benzo-fused frameworks. ${ }^{10}$ Remarkably, the reactions between arynes and organosulfur compounds have been widely investigated. As such, arynes can react with a variety of organosulfur compounds including S(II), S(IV), and S(IV) valence state, thus allows for the diversity-oriented synthesis of aromatic organosulfurs that are difficult to access by conventional methods. ${ }^{11,12}$ Among them, we are particularly interested in those reactions involves sulfonium ylides, a neutral 1,2dipolar species consisting of electron-rich carbon atom and an adjacent electro-positive sulfur atom. For example, nucleophilic attack of alkyl thioether towards aryne followed by intramolecular 1,4-proton shift contribute an elegant strategy for the formation of sulfonium ylides (Scheme 2a), which can be further applied to various conversions. ${ }^{13}$ Remarkably, this strategy has been established from various modes of trapping of HDDA-generated benzynes with sulfides by Hoye and coworkers. ${ }^{14}$ Recently, Studer and co-workers have disclosed that vinyl thioethers lacking $\alpha$-CH protons reacted with benzyne through direct $[3+2]$ cycloaddition to give cyclic sulfonium ylides. This methods eventually enables the preparation of
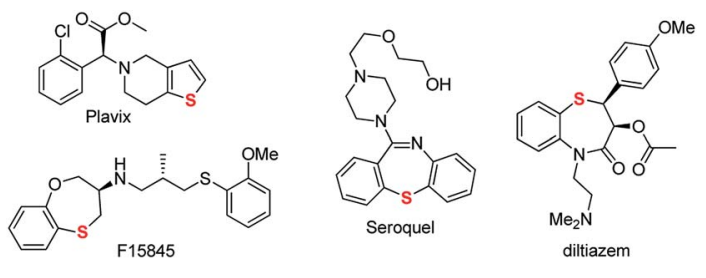

Scheme 1 Representative natural products and bioactive molecules with sulfur-containing ring. 
(a) Aryne monofunctionalization via intramolecular proton transfer<smiles>[R]O[Si]([R])c1ccc(CC)cc1</smiles>

(b) Aryne difunctionalization via [3+2] cycloaddtion

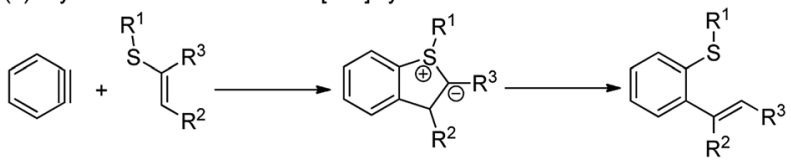

Scheme 2 Representative examples involving sulfonium ylide.

corresponding tetrasubstituted alkenes with high stereoselectivity (Scheme $2 \mathrm{~b}) .{ }^{15}$ In the past years, we have paid much attention to the aryne chemistry and the heterocycle synthesis. ${ }^{16,17}$ As a continuation, herein we report that the unprecedented reaction of arynes and methylenebenzothiopheneones enables the synthesis of structurally unusual benzo-fused eight-membered ring.

We commenced our investigation using benzyne precursor 1 and 2-methylenebenzothiophene-3-ones $\mathbf{4 a}$ as the model substrates. As shown in Table 1, heating the mixture of $\mathbf{1}$ and $\mathbf{4 a}$ in $\mathrm{CH}_{3} \mathrm{CN}$ with excessive $\mathrm{CsF}$ as fluorine source essentially afforded a new product $5 \mathbf{a}$ in $48 \%$ yield (Table 1, Entry 1). After that, reactions with other solvents including THF, toluene, 1,4dioxane and DCM were also performed to enhance the yield of 5a. Pleasingly, the experimental outcome revealed that the employment of DCM as the solvent significantly increased the

Table 1 Reaction optimization ${ }^{a}$

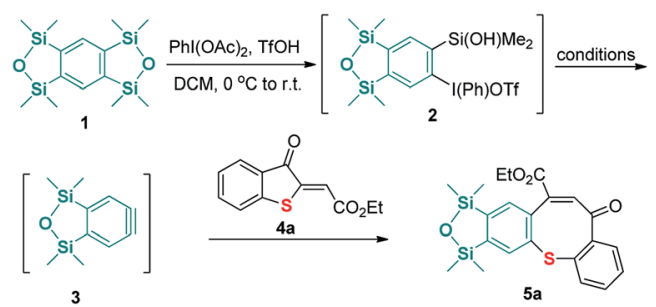

\begin{tabular}{llllll}
\hline Entry & F source & Equiv. of 1 & Solvent & Temp. $\left({ }^{\circ} \mathrm{C}\right)$ & Yield $^{b}(\%)$ \\
\hline 1 & CsF & 1.5 & CH $_{3}$ CN & 40 & 48 \\
2 & CsF & 1.5 & THF & 40 & 63 \\
3 & CsF & 1.5 & Toluene & 40 & 62 \\
4 & CsF & 1.5 & Dioxane & 40 & 59 \\
5 & CsF & 1.5 & DCM & Reflux & 87 \\
6 & CsF & 1.5 & DCM & rt & 65 \\
7 & CsF & 1.5 & DCM & $60^{d}$ & 79 \\
8 & CsF & 2.0 & DCM & Reflux & 82 \\
9 & CsF & 1.0 & DCM & Reflux & 75 \\
10 & TBAF & 1.5 & DCM & Reflux & 47 \\
11 & KF/18-c-6 & 1.5 & DCM & Reflux & 67 \\
12 & KF/18-c-6 & 1.5 & THF & Reflux & 71
\end{tabular}

${ }^{a}$ Unless otherwise noted, all reactions were carried out with $1.0 \mathrm{mmol} 2$ methylenebenzothiophene-3-one $\mathbf{4 a}$, fluorine source, in $3 \mathrm{~mL}$ solvent. ${ }^{b}$ Isolated yield. ${ }^{c} \mathrm{Bp}$ of DCM: $39.8^{\circ}{ }^{\circ} .^{d}$ Sealing reaction temperature. yield of 5a (Table 1, entries 2-5). Encouraged by these results, we then examined the present reactions with different reaction temperature, equivalence ratios and fluorine sources. The best performance was obtained when reaction was conducted under reflux and 1.5 equiv. of 1 (Table 1 , entries 5-9). Of the fluorine sources tested, KF/18-C- 6 and TBAF could not bring further improvement (Table 1, entries 10-12).

After the best conditions were obtained in hand, the feasibility of substituted 2-methylenebenzothiophene-3-ones 4 was next evaluated. As shown in Scheme 3, a variety of 2methylenebenzothiophene-3-ones $\mathbf{4}$ having substituents including methyl, tert-butyl, halo, and methoxyl groups at the position 7, 6, 5 of the aromatic ring were used to react with benzyne precursor 1 . All reactions worked well to produce the desired products $(\mathbf{5 a}-\mathbf{5 h})$. Additionally, when the ester moiety in substrate 4 was changed from OEt to OMe, OBn, or $\mathrm{O}^{t} \mathrm{Bu}$, the corresponding products $\mathbf{5 i - 5 k}$ were afforded in high
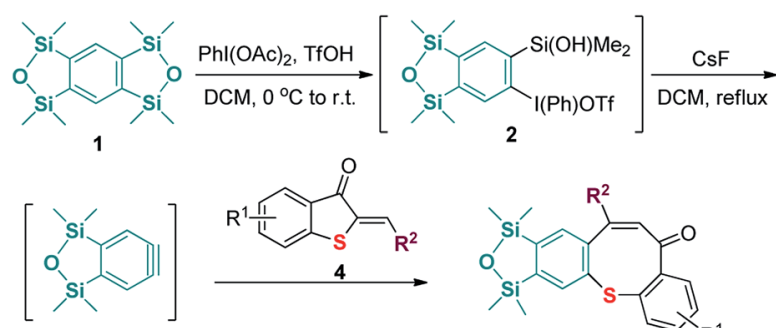

3
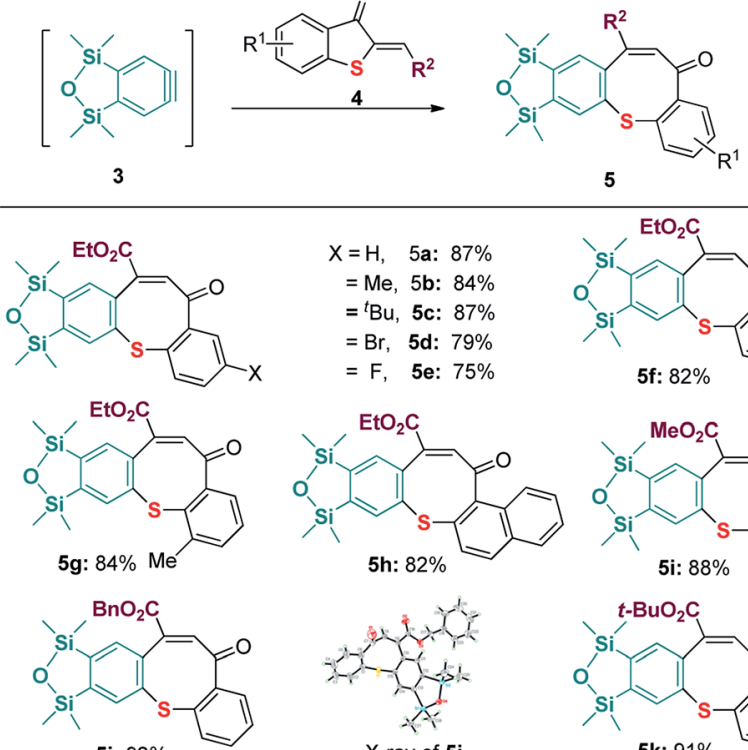

5j: $92 \%$
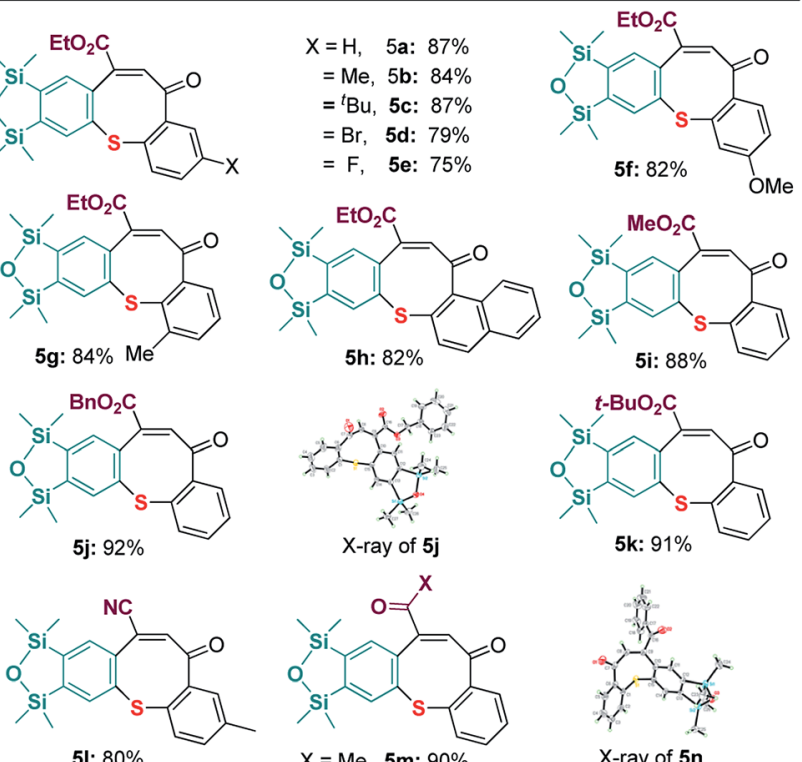

$\mathrm{X}$-ray of $\mathbf{5 j}$
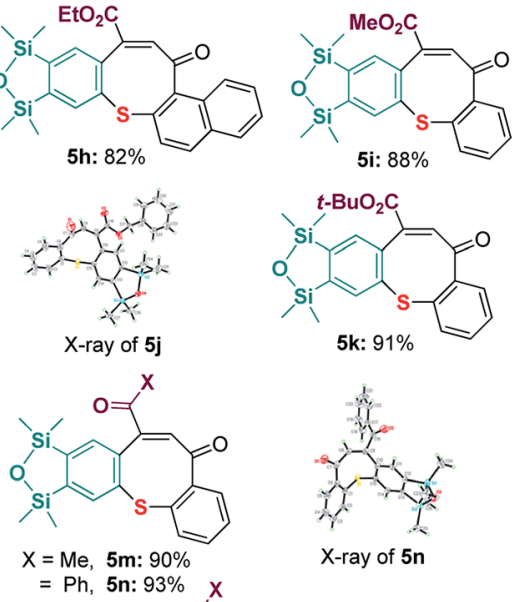

X-ray of $5 n$

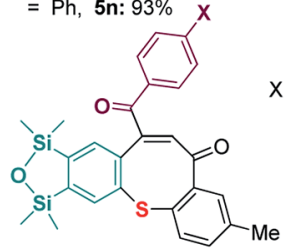

$X=M e, 5 p: 85 \%$

$=\mathrm{OMe}, 5 \mathrm{q}: 83 \%$

$=\mathrm{Cl}, \quad 5 \mathrm{r}: 77 \%$

$=\mathrm{NO}_{2}, \quad 5 \mathbf{s}: 82 \%$

Scheme 3 Substrate scope of the reaction with respect to the methylenebenzothiopheneone. Reaction condition: $1.5 \mathrm{mmol}$ benzyne precursor 1, $1.0 \mathrm{mmol}$ 2-methylenebenzothiophene-3-one 4, CsF $(3.0 \mathrm{mmol})$, in $3 \mathrm{~mL}$ DCM. Isolated yields are reported. 
performance. It was also worthy to note that when the electronwithdrawing groups such as cyano, and substituted carbonyl groups were employed instead of ester unit, the corresponding products 5l-5s were isolated in satisfactory yields. Furthermore, the structure of compounds $\mathbf{5 j}$ and $\mathbf{5 n}$ was unambiguously characterized by single-crystal X-ray analysis..$^{18}$

After a broad substrate scope with benzyne precursor was established, reactions of naphthyne precursor 6 and substituted 2-methylenebenzothiophene-3-ones were subsequently tested. As shown in Scheme 4, reactions with 2methylenebenzothiophene-3-ones 4 bearing different electronwithdrawing groups proceeded smoothly to produce products 9a-9e in satisfactory yield.

To gain more insight into the present reaction, several control experiments and preliminary mechanistic experiments were next conducted. As shown in Scheme 5, benzyne precursor ortho-(trimethylsilyl)aryltriflate $\mathbf{1 0 a}$ and $\mathbf{1 0 b}$ were proven to be compatible reaction partners to react with 2methylenebenzothiophene-3-ones 4 (Scheme 5, eqn (1) and (2)). After that, reactions with unsymmetrical benzyne precursor 10c and 10d were also examined (Scheme 5, eqn (3) and (4)). Pleasingly, only one isomer was detected when 3-methyl-2(trimethylsilyl)phenyl trifluoromethanesulfonate 10c was used. The isotope-labelling experiment with $10 a$ and $4 \mathbf{i}$ also revealed that deuterium was incorporated in the product to produce [D]11e (Scheme 5, eqn (5)). This result suggested that water was also involved in present transformation.

Based on the aforementioned results and previous reports, a plausible reaction mechanism is described in Scheme 6 . Firstly, the $[3+2]$ cycloaddition between 2methylenebenzothiophene-3-ones $\mathbf{4}$ and aryne yields a sulfonium ylide intermediate $\mathbf{B}$. In the presence of water, $\mathbf{B}$ is further protonated to deliver sulfonium salt $\mathbf{C}$. After that, the in situ generated hydroxide ion serves as a base to facilitate the following intramolecular $\beta$-elimination, thus providing a quick access to the product.
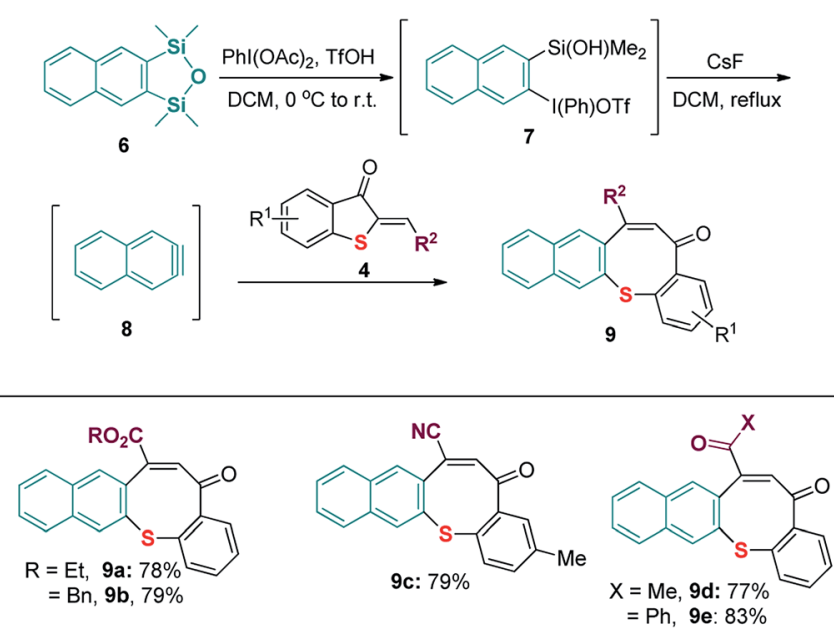

Scheme 4 Reaction conditions: $1.5 \mathrm{mmol}$ naphthyne precursor 6, 1.0 $\mathrm{mmol} 2$-methylenebenzothiophene-3-one 4, CsF (3.0 mmol), in $3 \mathrm{~mL}$ DCM. Isolated yields are reported.
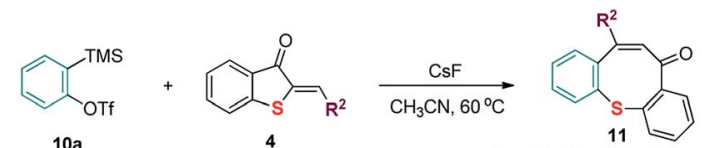

$10 \mathrm{a}$

$$
\begin{aligned}
\mathrm{R}^{2} & =\mathrm{CO}_{2} \mathrm{Et}, \quad 11 \mathrm{a}: 87 \% \\
& =\mathrm{CO}_{2} \mathrm{Bn}, 11 \mathrm{~b}: 73 \% \\
& =\mathrm{COPh}, \quad 11 \mathrm{c}: 80 \%
\end{aligned}
$$
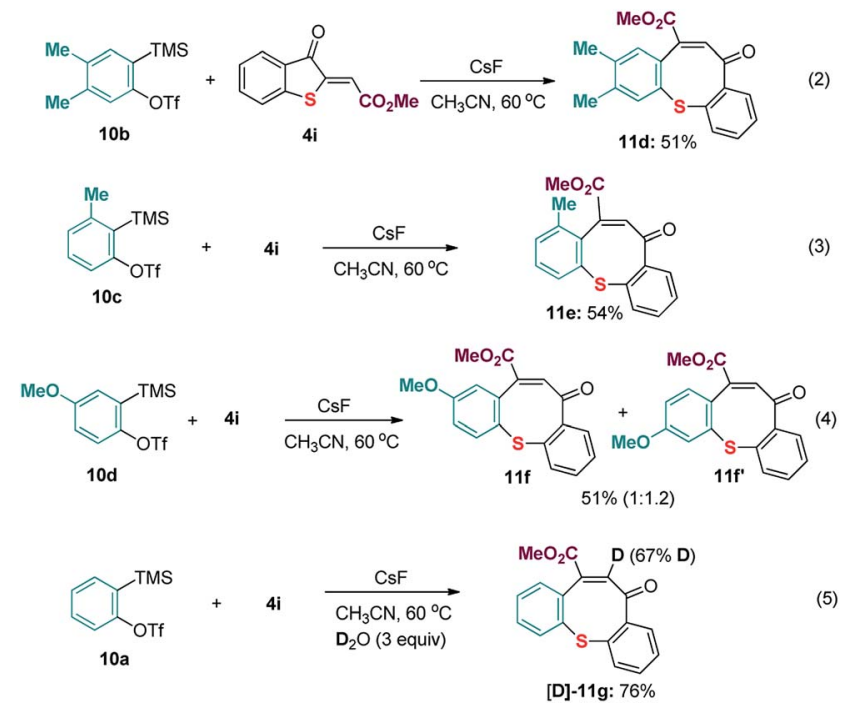

Scheme 5 Control experiments and preliminary mechanistic studies.

To further explore the application of present reaction, an oxidation reaction of the products was also attempted. In the presence of $\mathrm{H}_{2} \mathrm{O}_{2},{ }^{19}$ the resultant sulfide products $5 \mathbf{k}$ and $5 \mathbf{s}$ experienced oxidation to corresponding functionalized sulfones 12a and 12b in an efficient and environmentally friendly manner (Scheme 7, eqn (1) and (2)).

In conclusion, we have described an unprecedented reaction from in situ generated aryne and 2-methylenebenzothiophene3-ones. This strategy allows for a new approach to benzofused eight-membered ring containing sulfur, which was difficult to be synthesized by traditional methods. Mechanistically, this reaction proceeds through cycloaddition, proton shift, intramolecular $\beta$-elimination, and the formation of sulfonium ylide. Further study and application of the present reaction

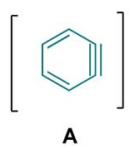

A<smiles>[R]C1=CC(=O)c2ccccc2Sc2ccccc21</smiles>
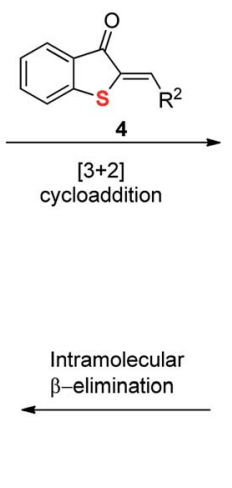

cycloaddition

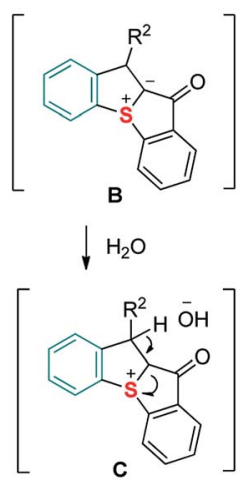

Scheme 6 Possible mechanism. 

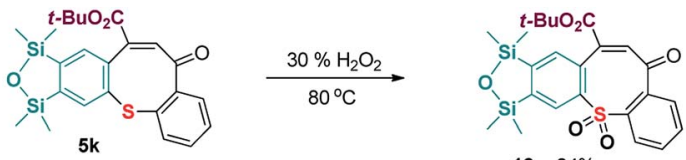

(1)
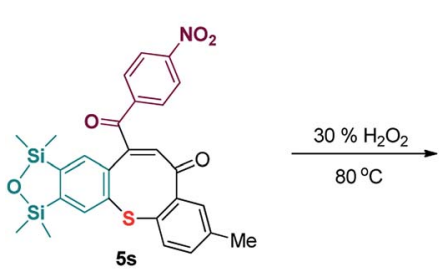

12a: $84 \%$

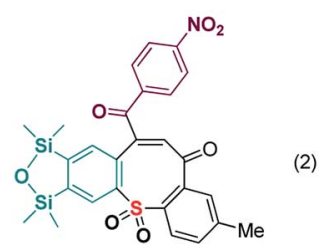

12b: $79 \%$
Scheme 7 Further application of the products.

including the biological detection are still underway in our laboratory.

\section{Conflicts of interest}

There are no conflicts to declare.

\section{Acknowledgements}

We thank the National Natural Science Foundation of China (No. 21272146) and the State Key Laboratory of Applied Organic Chemistry, Lanzhou University for financial support. This work is also sponsored by Natural Science Foundation of Shanghai (18ZR1413900).

\section{Notes and references}

1 (a) E. A. Ilardi, E. Vitaku and J. T. Njardarson, J. Med. Chem., 2014, 57, 2832; (b) Sulfur Compounds: Advances in Research and Application, ed. A. Q. Acton, Scholarly Editions, Atlanta, GA, 2012.

2 Please find the data reflecting the top 200 rankings from http://www.pharmacytimes.com/publications/issue/2012/ July2012/Top-200-Drugs-of-2011, 2012.

3 (a) K. Asano and S. Matsubara, ACS Catal., 2018, 8, 6273; (b) H. Kugita, H. Inoue, M. Ikezaki, M. Konda and S. Takeo, Chem. Pharm. Bull., 1970, 18, 2284.

4 (a) W. He, Z. Zhang and D. Ma, Angew. Chem., Int. Ed., 2019, 58, 3972; (b) J. Chen, X. Chen, M. Bois-Choussy and J. Zhu, J. Am. Chem. Soc., 2006, 128, 87.

5 For selected reviews on aryne chemistry, see: (a) H. Takikawa, A. Nishii, T. Sakai and K. Suzuki, Chem. Soc. Rev., 2018, 47, 8030; (b) T. Roy and A. T. Biju, Chem. Commun., 2018, 54, 2580; (c) J. Shi, Y. Li and Y. Li, Chem. Soc. Rev., 2017, 46, 1707; (d) S. Yoshida and T. Hosoya, Chem. Lett., 2015, 44, 1450; (e) D. Pérez, D. Peña and E. Guitián, Eur. J. Org. Chem., 2013, 5981; $(f)$ C. M. Gampe and E. M. Carreira, Angew. Chem., Int. Ed., 2012, 51, 3766; (g) P. M. Tadross and B. M. Stoltz, Chem. Rev., 2012, 112, 3550; (h) A. Bhunia, S. R. Yetra and A. T. Biju, Chem. Soc. Rev., 2012, 41, 3140.
6 For selected examples, see: (a) Y. Nakamura, Y. Miyata, K. Uchida, S. Yoshida and T. Hosoya, Org. Lett., 2019, 21, 5252; (b) S. Bhattacharjee, A. Guin, R. N. Gaykar and A. T. Biju, Org. Lett., 2019, 21, 4383; (c) J. Zhao, H. Li, P. Li and L. Wang, J. Org. Chem., 2019, 84, 9007; (d) H. Xu, J. He, J. Shi, L. Tan, D. Qiu, X. Luo and Y. Li, J. Am. Chem. Soc., 2018, 140, 3555; (e) S. Yoshida, T. Yano, Y. Misawa, Y. Sugimura, K. Igawa, S. Shimizu, K. Tomooka and T. Hosoya, J. Am. Chem. Soc., 2015, 137, 14071; (f) Y. Nagashima, R. Takita, K. Yoshida, K. Hirano and M. Uchiyama, J. Am. Chem. Soc., 2013, 135, 18730; $(g)$ T. Kitamura, Z. Meng and Y. Fujiwara, Tetrahedron, 2000, 41, 6611.

7 (a) U. K. Tambar and B. M. Stoltz, J. Am. Chem. Soc., 2005, 127, 5340; (b) U. K. Tambar, D. C. Ebner and B. M. Stoltz, J. Am. Chem. Soc., 2006, 128, 11752; (c) R. Samineni, C. R. C. Bandi, P. Srihari and G. Mehta, Org. Lett., 2016, 18, 6184; (d) P. Gouthami, R. Chegondi and S. Chandrasekhar, Org. Lett., 2016, 18, 2044.

8 (a) J. Schwan, M. Kleoff, B. Hartmayer, P. Heretsch and M. Christmann, Org. Lett., 2018, 20, 7661; (b) A. C. Wright, C. K. Haley, G. Lapointe and B. M. Stoltz, Org. Lett., 2016, 18, 2793; (c) Z. Liu and R. C. Larock, J. Am. Chem. Soc., 2005, 127, 13112; (d) H. Yoshida, E. Shirakawa, Y. Honda and T. Hiyama, Angew. Chem., Int. Ed., 2002, 41, 3247; (e) N. Saito, K. Nakamura, S. Shibano, S. Ide, M. Minami and Y. Sato, Org. Lett., 2013, 15, 386.

9 (a) R. N. Gaykar, S. Bhattacharjee and A. T. Biju, Org. Lett., 2019, 21, 737; (b) S. J. Li, Y. Wang, J. K. Xu, D. Xie, S. K. Tian and Z. X. Yu, Org. Lett., 2018, 20, 4545; (c) J. A. García-López, M. Çetin and M. F. Greaney, Angew. Chem., Int. Ed., 2015, 54, 2156; (d) T. Matsuzawa, K. Uchida, S. Yoshida and T. Hosoya, Org. Lett., 2017, 19, 5521; (e) S. Yoshida, Y. Nakamura, K. Uchida, Y. Hazama and T. Hosoya, Org. Lett., 2016, 18, 6212; (f) H. Yoshida, J. Ikadai, M. Shudo, J. Ohshita and A. Kunai, J. Am. Chem. Soc., 2013, 125, 6638; (g) K. Z. Łączkowski, D. García, D. Peña, A. Cobas, D. Pérez and E. Guitián, Org. Lett., 2011, 13, 960 .

10 (a) S. S. Bhojgude, A. Bhunia and A. T. Biju, Acc. Chem. Res., 2016, 49, 1658; (b) V. Dubrovskiy, N. A. Markina and R. C. Larock, Org. Biomol. Chem., 2013, 11, 191; (c) Z. Wang, Y. Addepalli and Y. He, Org. Lett., 2018, 20, 644; (d) D. Xu, Y. Zhao, D. Song, Z. Zhong, S. Feng, X. Xie, X. Wang and X. She, Org. Lett., 2017, 19, 3600.

11 For a recent review on aryne reactions with organosulfurcompounds, see: T. Matsuzawa, S. Yoshida and T. Hosoya, Tetrahedron Lett., 2018, 59, 4197.

12 For selected examples, see: (a) P. Garg and A. Singh, Org. Lett., 2018, 20, 1320; (b) T. Zheng, J. Tan, R. Fan, S. Su, B. Liu, C. Tan and K. Xu, Chem. Commun., 2018, 54, 1303; (c) J. Shi, D. Qiu, J. Wang, H. Xu and Y. Li, J. Am. Chem. Soc., 2015, 137, 5670; (d) S. Yoshida, K. Uchida, K. Igawa, T. Tomooka and T. Hosoya, Chem. Commun., 2014, 50, 15059; (e) F. L. Liu, J. R. Chen, Y. Q. Zou, Q. Wei and W. J. Xiao, Org. Lett., 2014, 16, 3768; (f) S. K. Aithagani, S. Dara, G. Munagala, H. Aruri, M. Yadav, S. Sharma, 
R. A. Vishwakarma and P. P. Singh, Org. Lett., 2015, 17, 5547; (g) J. Nakayama, T. Fujita and M. Hoshino, Chem. Lett., 1983, 249.

13 H. D. Xu, M. Q. Cai, W. J. He, W. H. Hu and M. H. Shen, RSC Adv., 2014, 4, 7623.

14 J. Chen, V. Palani and T. R. Hoye, J. Am. Chem. Soc., 2016, 138, 4318.

15 Y. Li, C. Mgck-Lichtenfeld and A. Studer, Angew. Chem., Int. Ed., 2016, 55, 14435.

16 (a) S. Su, J. Li, M. Sun, H. Zhao, Y. Chen and J. Li, Chem. Commun., 2018, 54, 9611; (b) K. Kong, J. Zhang, P. Zhao, H. Lu, Z. Chen, W. Cao, J. Chen and Y. Chen, Tetrahedron, 2017, 73, 6742; (c) J. Li, N. Wang, C. Li and X. Jia, Org.
Lett., 2012, 14, 4994; (d) Y. Chen, C. Hau, H. Wang, H. He, M. Wong and A. Lee, J. Org. Chem., 2006, 71, 3512; (e) Y. Chen, J. Sun, X. Wei, W. Wong and A. Lee, J. Org. Chem., 2004, 69, 7190.

17 (a) B. Xue, S. Su, Y. Cui, Y. Fei, X. Jia, J. Li and J. Fang, Chem. Commun., 2019, 55, 12180; (b) J. Hu, Y. Fei, H. Zhao, Z. Wang, C. Li and J. Li, Chem. Commun., 2019, 55, 8394; (c) H. Yuan, C. Tang, S. Su, L. Cui, X. Jia, C. Li and J. Li, Chem. Commun., 2019, 55, 7231; (d) T. Jin, Z. Tang, J. Hu, H. Yuan, Y. Chen, C. Li, X. Jia and J. Li, Org. Lett., 2018, 20, 413.

18 CCDC 1915323, 1915320 for compound $\mathbf{5 j}$, 5n contain the supplementary crystallographic data for this paper.

19 M. Jereb, Green Chem., 2012, 14, 3047. 